\title{
Áncash en broma
}

\author{
Wilfredo Kapsoli Escudero \\ Universidad Ricardo Palma \\ wckapsoli@hotmail.com \\ Lima-Perú
}

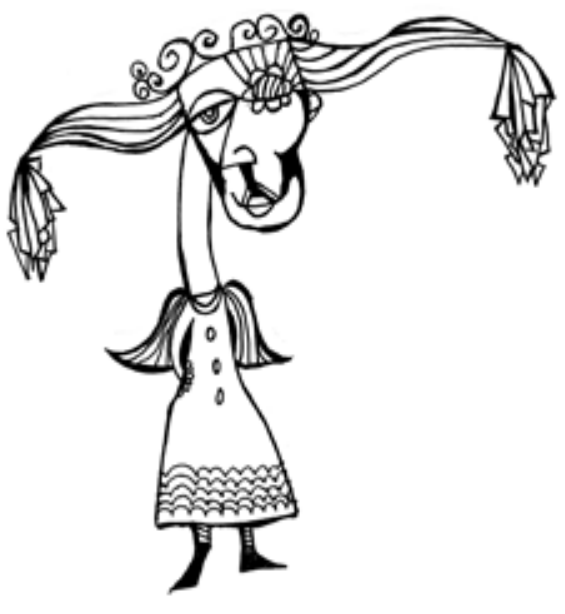

\section{Introducción}

Adelmo Vidal Rodríguez, pintor ancashino, nos ha sorprendido gratamente con el arte que cultiva. Y con la modestia que lo caracteriza ha preparado la "exposición de sus dibujos", que nosotros lo hemos calificado como Áncash en broma que no posee antecedentes en este género y contenido. En tal sentido, Adelmo Vidal Rodríguez, con su elevado espíritu humorístico, ha penetrado hondamente en la íntima y vivencial sicología de los ancashinos, bebiendo de su rico folklore, múltiple gama de apodos y vituperios típicos penetrados profundamente en el contexto semántico. La colección es una muestra de la idiosincrasia espontánea, fresca y profunda, de nuestros paisanos.

Adelmo Vidal nos deleita con su ingenio y creatividad artística. Lo hizo antes con su galería -burlesca a partir de los apodos provinciales y distritales del Departamento. Así, Carhuaz "borrachera", Huaraz "presunción", Pomabamba "lacia mula", etc. Le sirvieron de tema y de pretexto para ilustrarlo.

\section{Abstract}

In many places of Peru (coast, highlands and jungle), it is a tradition that the inhabitants of each locality create humorous and derogatory nicknames related with nature, economic and social activities and festivities of each geographical space. In the case of the Department of Ancash, the Italian traveler Antonio Raimondi was the one who recorded in his memoirs the festive vocabulary of each district and province. The painter and caricaturist Adelmo Vidal, has prepared a sample of his artistic production, which we will discuss on this occasion.

Keywords: Nicknames, humorisms, alias, traditions, festivities.

Una cita bíblica, un dicho popular y el simple sentido común le permiten a Adelmo sazonar su arte que nos entrega adobado con el fragor de su pluma y delicadamente rociado con su mirada zorrina de auténtico piscobambino. Y su generosidad es tal, que nos invita a un verdadero banquete donde abunda la carne -de ave y de res-, los cereales -aunque fosilizados-, la leche y hasta "el agüita clara de Curayacu”. No podían faltar la guitarra y el violín, el 
pico, la pala y la plomada, que, si se da el caso, podrían servir de instrumento. Adelmo, además es previsor: si no les gusta el festín que se recluyan en los libros o elijan sus "bochas". Señores ... ¡La mesa está servida! Pero, no nos apresuremos. Nuestro hambre no podrá ser satisfecho porque el "larguirucho" Teodomiro, "el mediocristiano" Hugo y Roque, el Presidente, nos dan el "Abicho" de que estamos entre amigos y que, cada uno a nuestra manera somos devotos de "Nicacho" quien, para salvar su nombre de pila, nos aconseja "no descuidar la cabeza, la barriga y el pajarito". De tal modo que, no nos queda sino reírnos como lo hacían nuestros abuelos en Huaraz "paraíso de mujeres, purgatorio de hombres e infierno de borricos".

\section{Caricaturas humorísticas}

Para seguir con la tonada ¡Salud a todos! Que como el gañán o garañón nos mantendremos cañón. Pasemos ahora a deleitar nuestros ojos y alegrar nuestros corazones con las caricaturas alusivas a los apodos de nuestros paisanos del Departamento de Áncash.

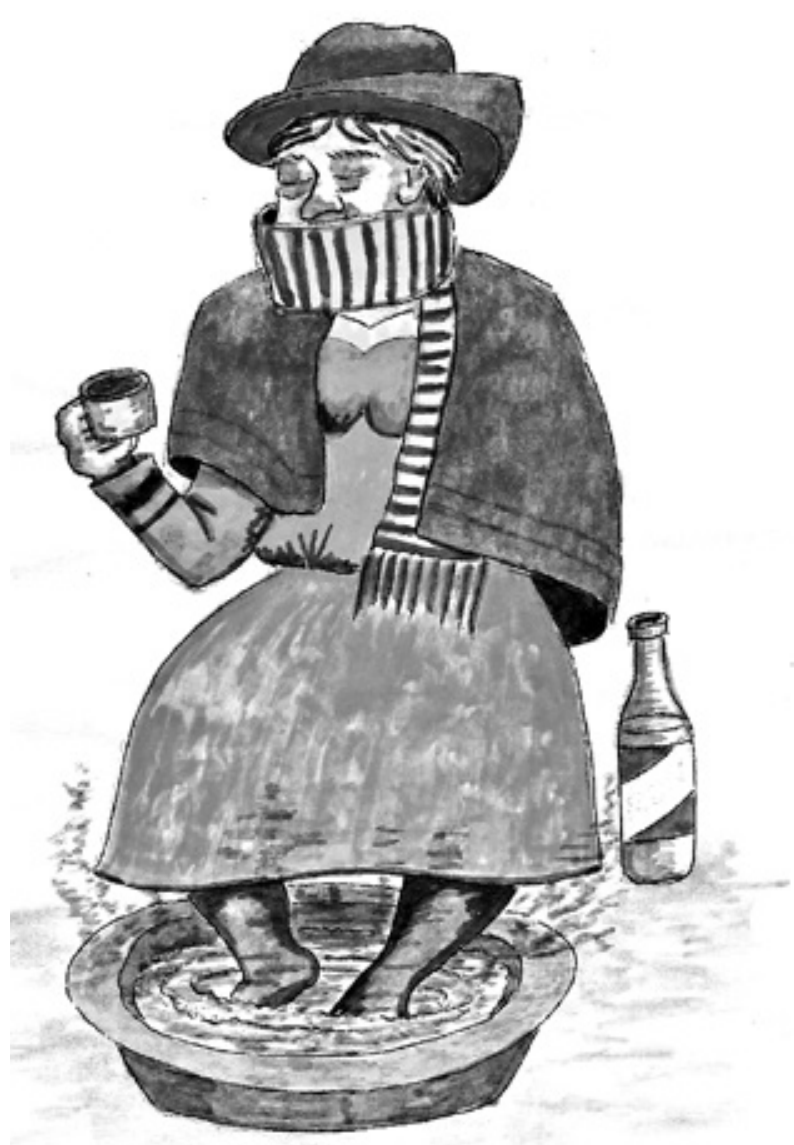

Huaraz Alalajj $=$ (mucho frío). Sus moradores deben contrarrestar por todos los medios el friaje natural del invierno. Generalmente lo hacen tomando su "calientito" (té caliente mezclado con alcohol).

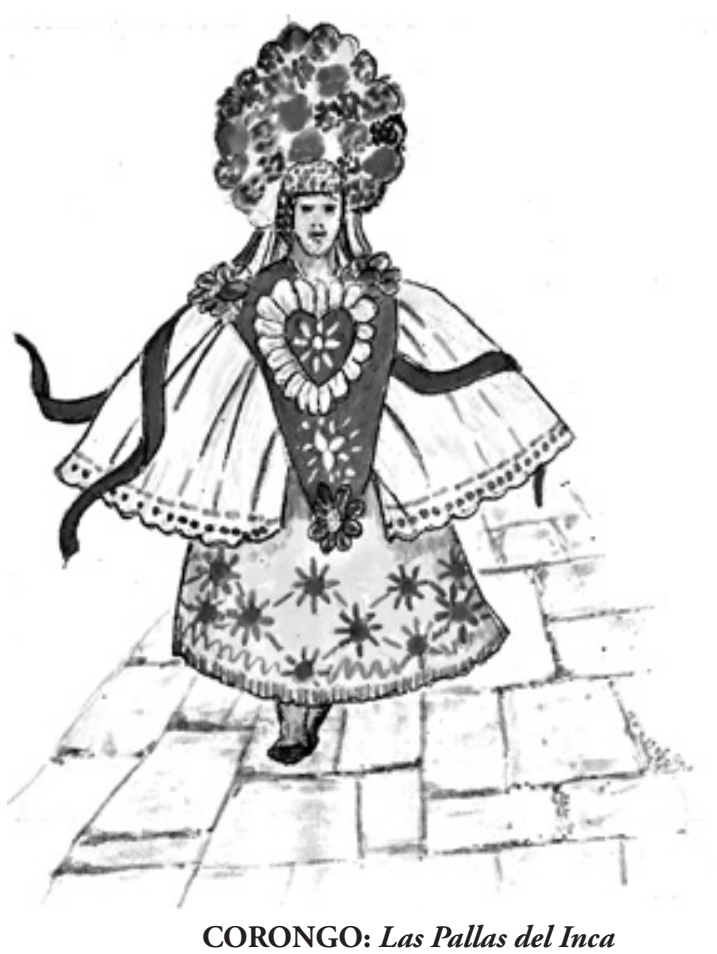

La Historia de Corongo se remonta a épocas primigenias, cuando surge en primera instancia como tribu y posteriormente como parte de una confederación de tribus, parte del señorío tribal Purunmarcas.

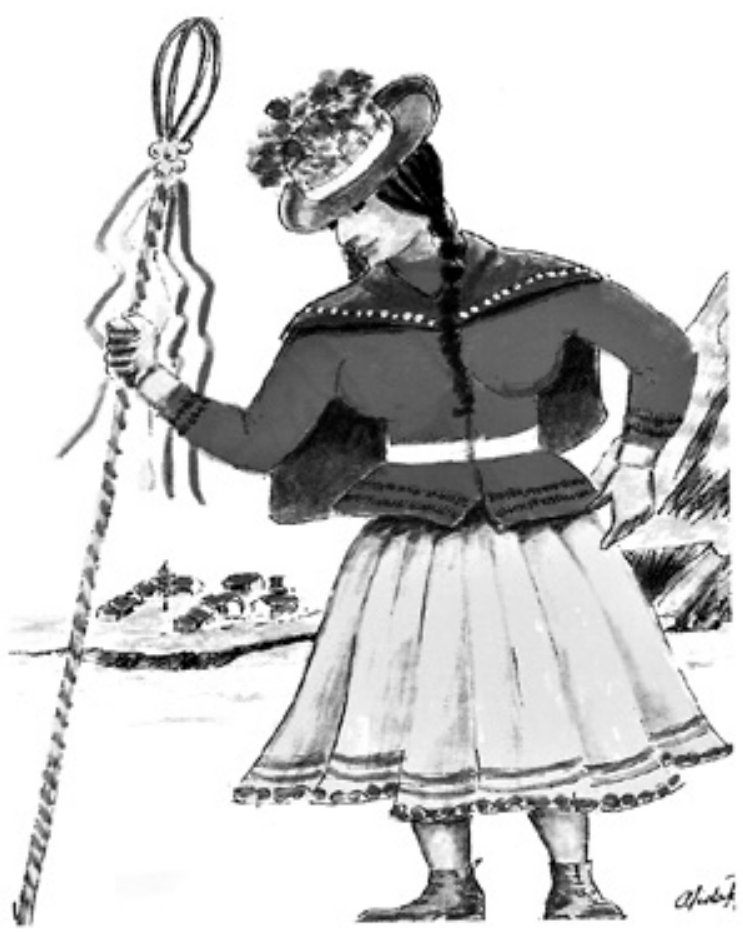

Bastón: Este conjunto femenino lo conforman 8 o 9 bailarinas. Un guía o "yachajj” que hace la primera voz cantante, el resto responde en coro.

Golpean el suelo con la vara (quiyaya), por eso el nombre del grupo, en su extremo superior. Las ramas hacen un arco y están adornados con cintas y cascabeles. 


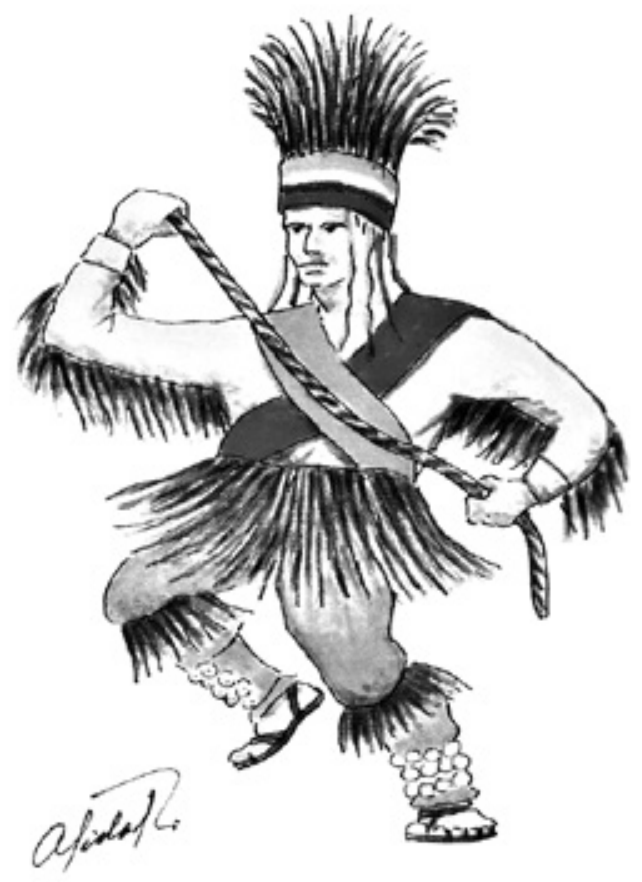

Huallpa Tushu (Baile de la Gallina). Se debe a la gran cantidad de plumas que ostenta en su vestuario. Cajas y pinkullos acompañan musicalmente a estos bailarines. Los cascabeles sujetos al tobillo son sacudidos con fuerza, hacen maromas con el fuerte y bullicios agradables.

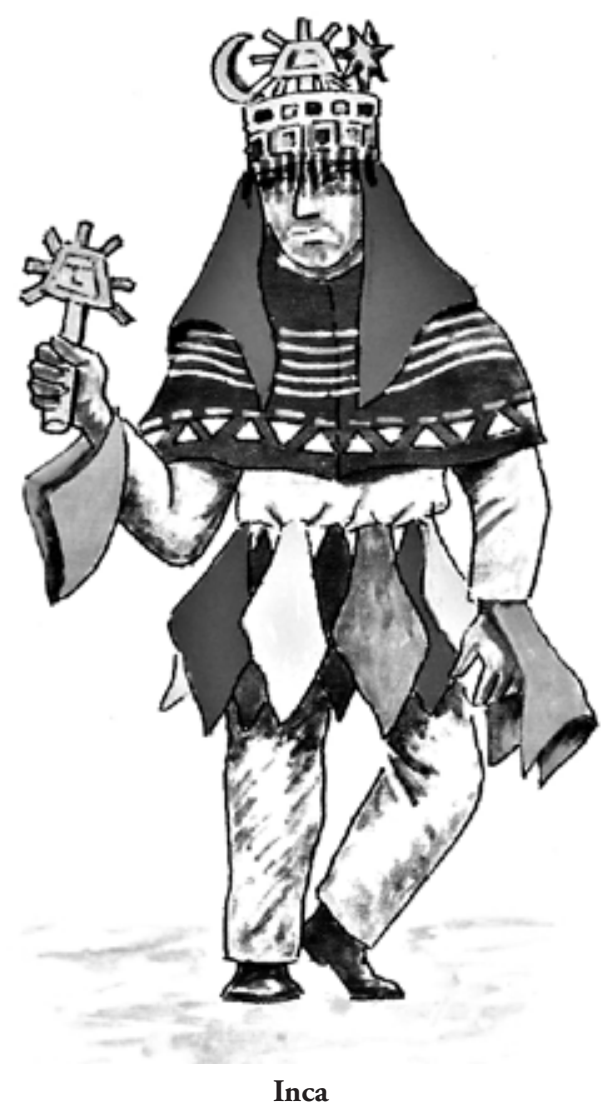

Es la comparsa más numerosa, la integran 20 personas. Vestimenta compleja y lujosa; música, monótona y melancólica en las cuerdas de arpa y violín, animándose al final en el pasacalle con un alegre chimaichi. La guiadora (Yachajj) canta estrofas al Apu Inca, al Inti (Sol), Quilla (Luna) dioses tutelares; las pallas responden en coro (Adiós, a Dios) finalizando con el estribillo: "ayllihuilla... aylliyahuilla...".

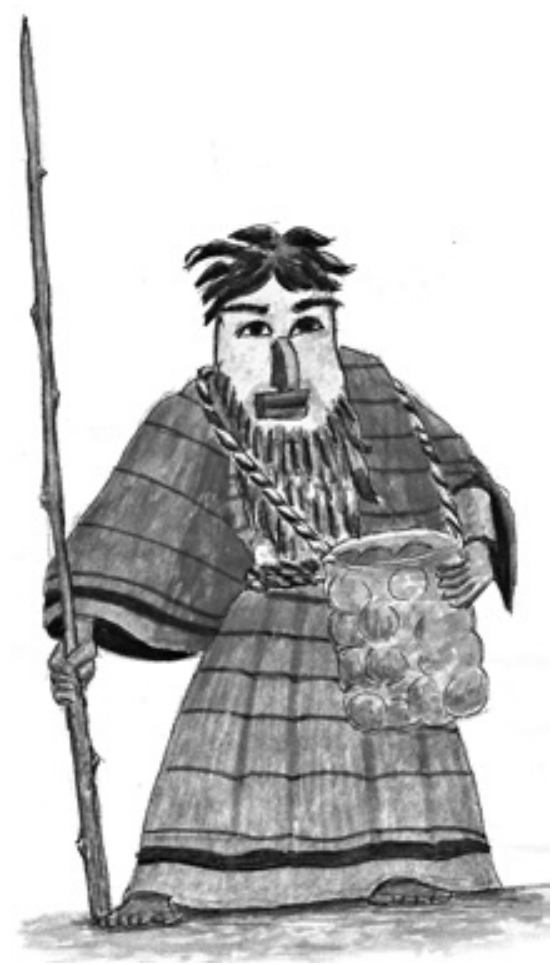

Tribu Selvática

Piscobamba: Augga. Esta comparsa representa a una fiesta de San Pedro, escenifican con el Anti (otra comparsa) una disputa territorial.

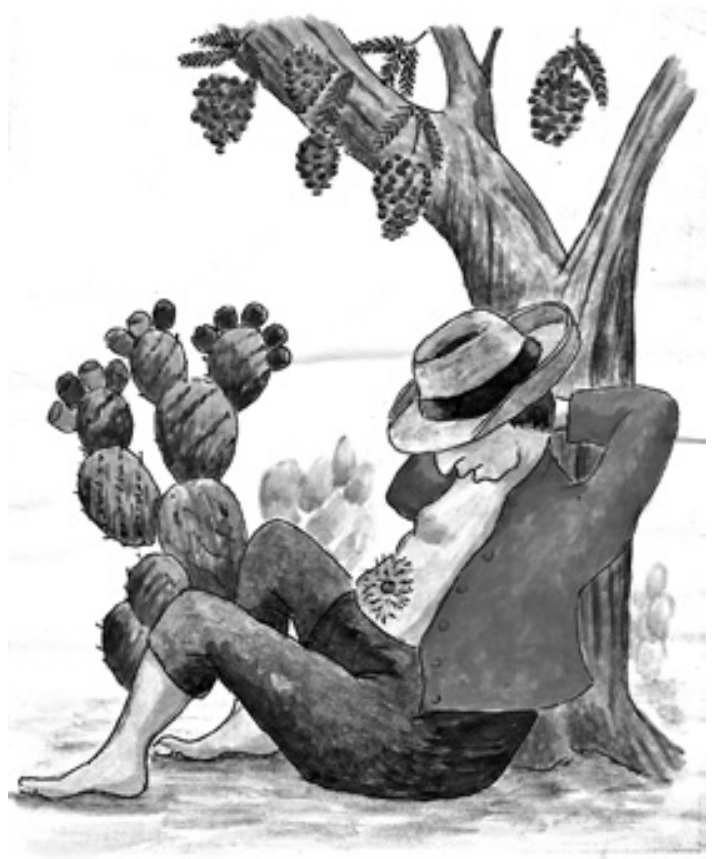

Shisu Pupu (ombligo con espinas)

Llumpa, Distrito de Luzuriaga. La abundancia de tunas y molle genera este apodo. 


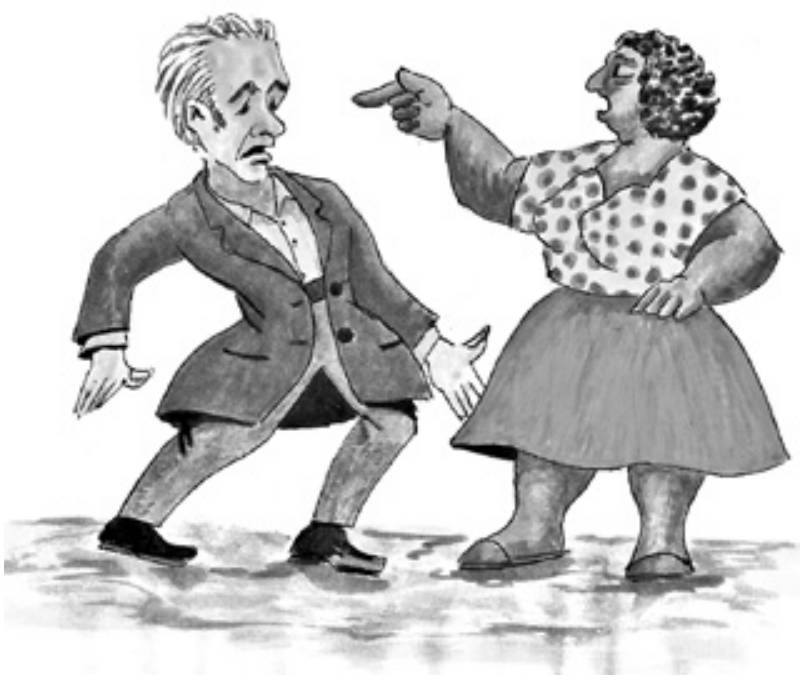

Huarmimandanam

Este apodo se debe al mandado por la mujer (sacolargo).

Se dice a los de Huarmey.

Cuando el arzobispo Toribio de Mogrovejo visitó el pueblo el 20 de agosto de 1593, halló a 910 indios.

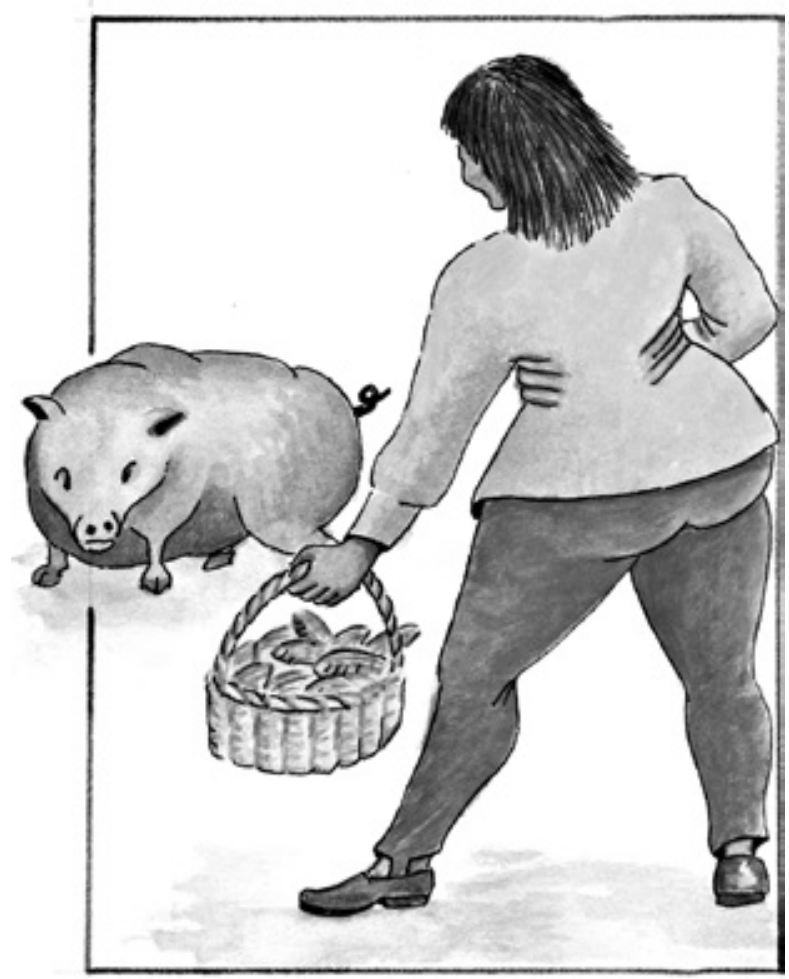

Sikisapa ¡Qué buen culo! En Yanama se dice que sin culo dońa Culli (Corina)... Es por la abundancia de los cerdos para el uso doméstico y para los negocios.

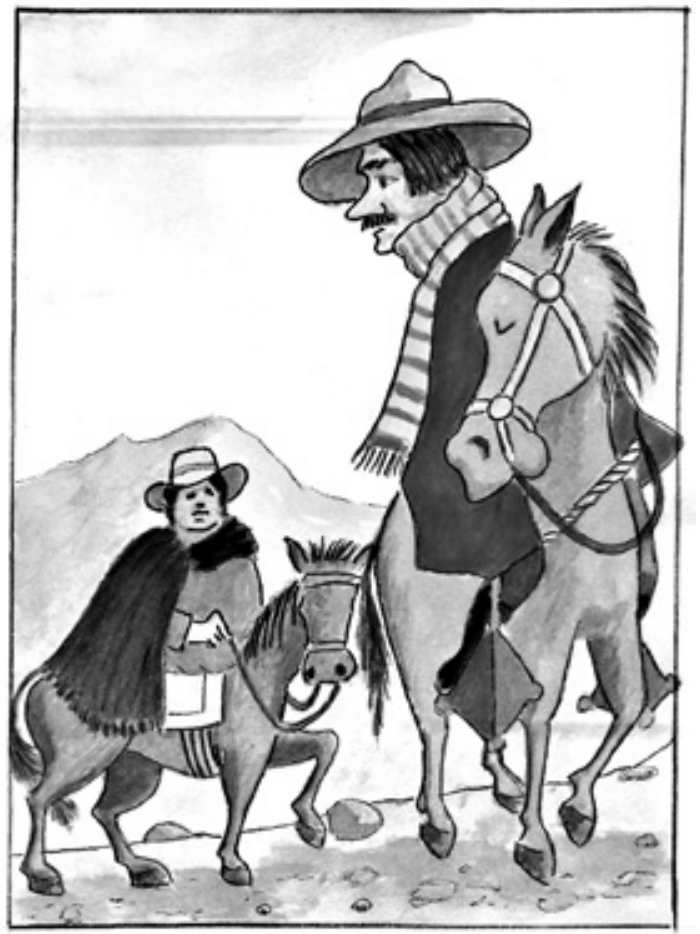

- ¡Nogga machajj...! -(yo a emborracharme)- Huarmii huachajj...! - (a parir mi mujer) se dice un Pomabamba.

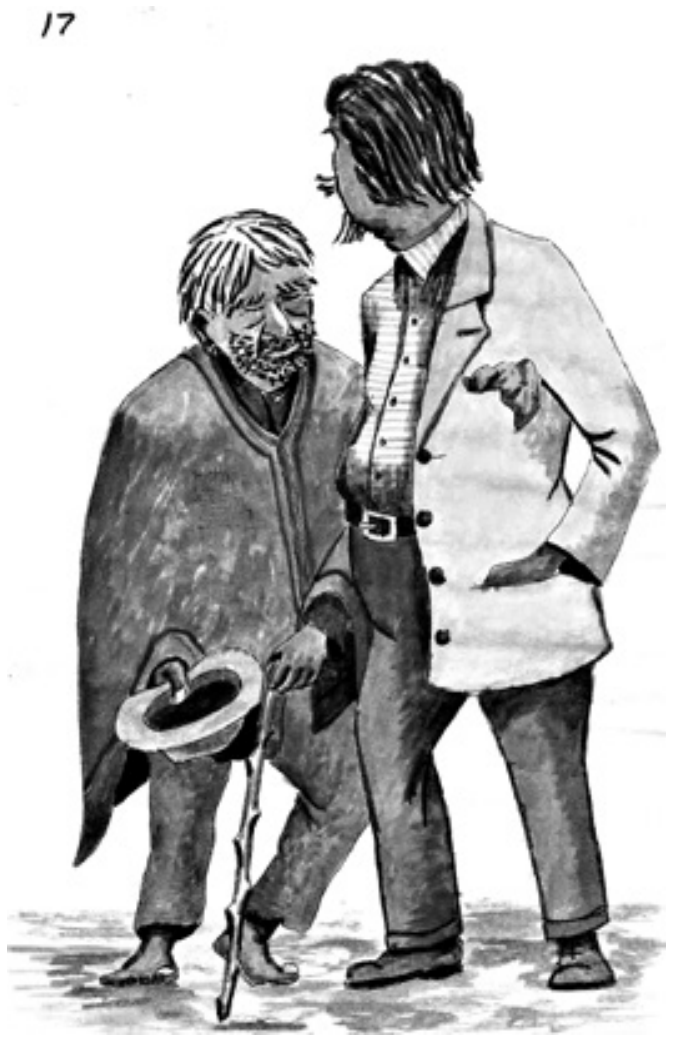




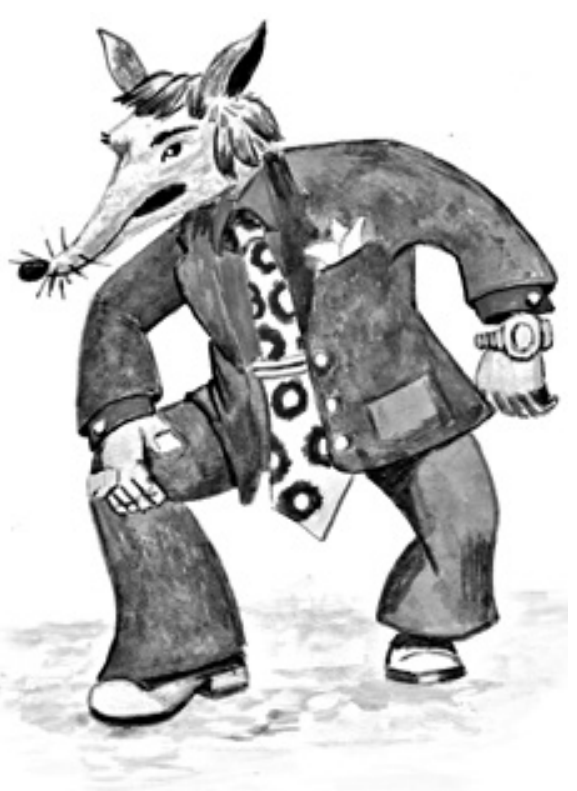

Atojjshaicu: zorro cansado, pretencioso.

En el año 2006 tenía una población de 4301 habitantes y una densidad poblacional de 55,6 personas por $\mathrm{km}^{2}$. Fue creado por la Ley No 9986 el 17 de octubre de 1944 promulgada por el presidente Manuel Prado Ugarteche.

(Kapsoli, Wilfredo y Ocaña, Helí. Áncash Capital Cultural y Educación. Lima, Ed. Derrama Magisterial. 2014, p. 430).

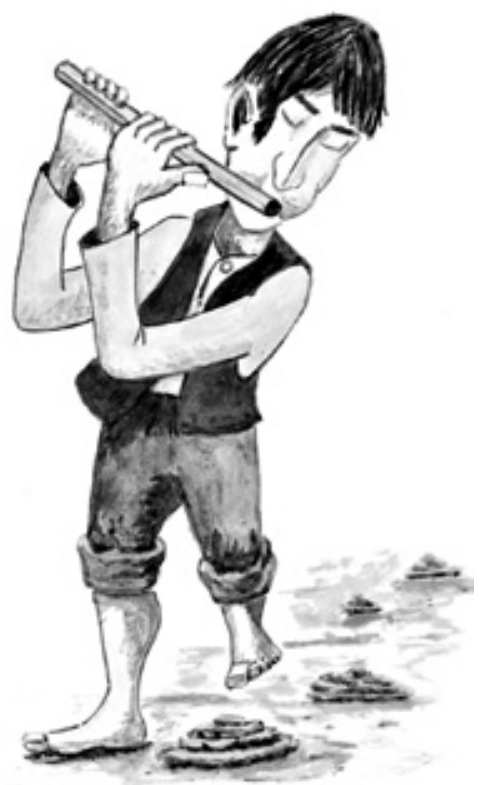

Flautero, ismay jaitajj: (toca y patea estiércol del ganado).

El distrito de Lucma es un distrito administrativo de la provincia de Mariscal Luzuriaga.
Fue creado por la ley $\mathrm{N}^{\circ} 13424$ del 3 de mayo de 1960, como una escisión del distrito de Llumpa.

Su capital es el pueblo de Lucma a una altitud de 2969 msnm. El distrito lo integran los pueblos de Masqui y Seccha y los caseríos de Chárac, Tayá, Puchgoj, Carhuacasha y Quíshuar, según su ley de creación; sin embargo, por los datos censales aparecen otros poblados de más. Tiene una superficie de 77,37 km². (Kapsoli, Wilfredo y ocaña, Helí. Op. Cit. p.432).

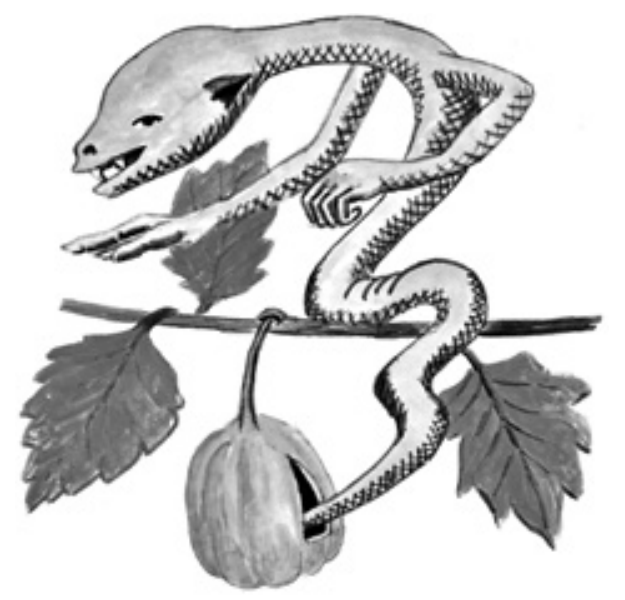

Shapash Estribo; Garua culebra (culebra amarilla) usa el zapallo como escribo.

Llama es uno de los ocho distritos de la Provincia de Mariscal Luzuriaga. En su creación intervino su hijo natural, el obispo de Ayacucho, Mons. Fidel Olivas Escudero.Su capital, el pueblo del mismo nombre, tiene una altitud de 2821 m.s.n.m y goza de un clima templado.

(Kapsoli, Wilfredo y Ocaña, Helí. Op. cit p. 431).

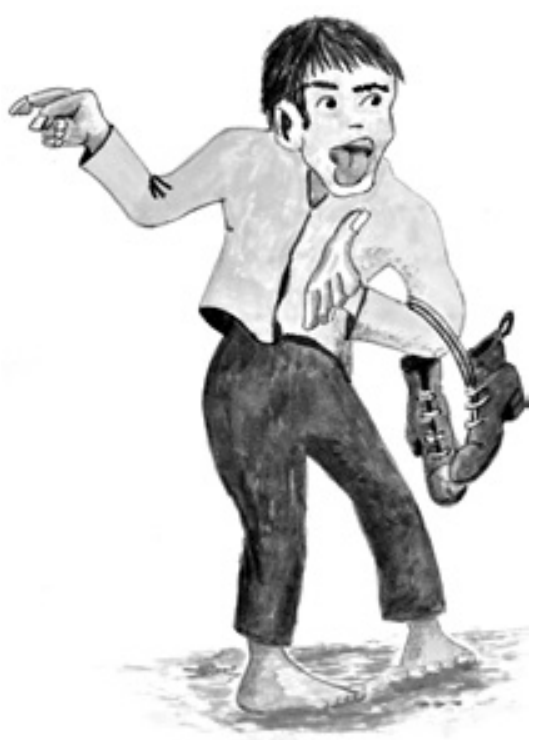

MUSGA Zapatun janchajj (litigante): Siempre en pleitos judiciales. Usa los zapatos solo en la ciudad. 
Musga es uno de los ocho distritos de la Provincia de Mariscal Luzuriaga.

Nace a la vida político-administrativa el 12 de mayo de 1962, por efecto de la Ley 14075, promulgada por Manuel Prado. En la gestión jugó un rol importante el distinguido personaje luzuriaguino, Marcelino Ocańa Meléndez. Se constituye desmembrando gran parte del territorio del distrito de Piscobamba, y el de Llama.

(Kapsoli, Wilfredo y Ocaña, Helí. Loc. cit.)

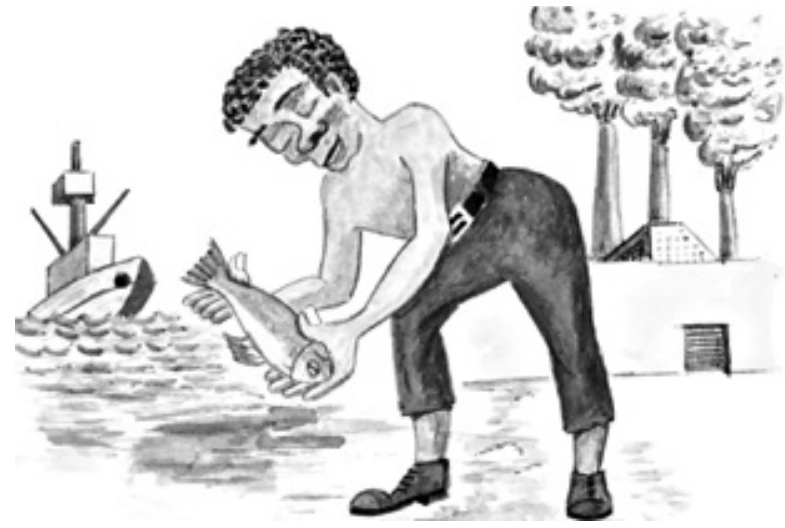

Pata salada: (Tanto estar en el mar, resultan con los pies salados).

Chimbote: Creada por Reglamento Provincial de 12 de febrero de 1821. Con 33,955 hbs. 7,128 $\mathrm{km}^{2}$. En la Costa de Pacífico. El puerto Mayor de Chimbote, inexpugnable, estratégico es la ciudad de más grandioso porvenir en el litoral peruano.

(Kapsoli, Wilfredo y Ocaña, Helí. Op. Cit, p. 432.)

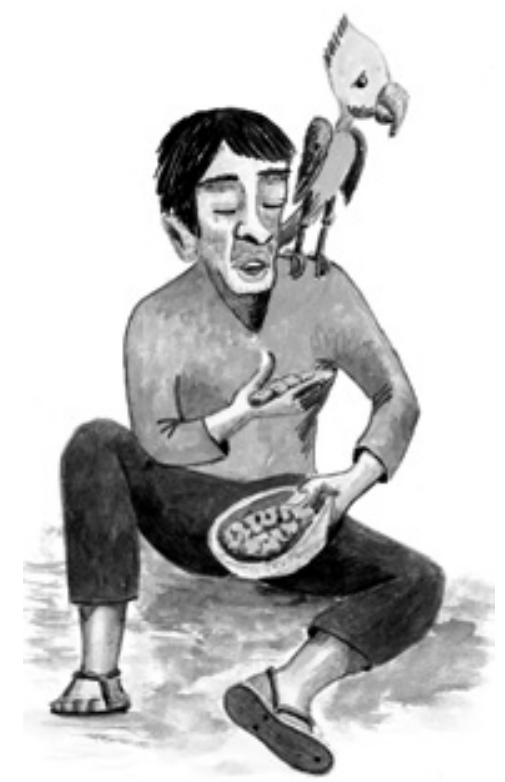

Ogga picante; liclish huatajj: (picante de ocas. Cría cernícalo).
Quinuabamba es uno de los cuatro distritos que conforman la provincia de Pomabamba.

Se creó por efecto de la Ley 9378 del 26 de setiembre de 1941, promulgada por Manuel Prado Ugarteche. Al erigirse como entidad distrital lo hace desmembrando el territorio de Parobamba, hacia la parte meridional.

(Kapsoli, Wilfredo y Ocaña, Helí. Op. cit p. 433).

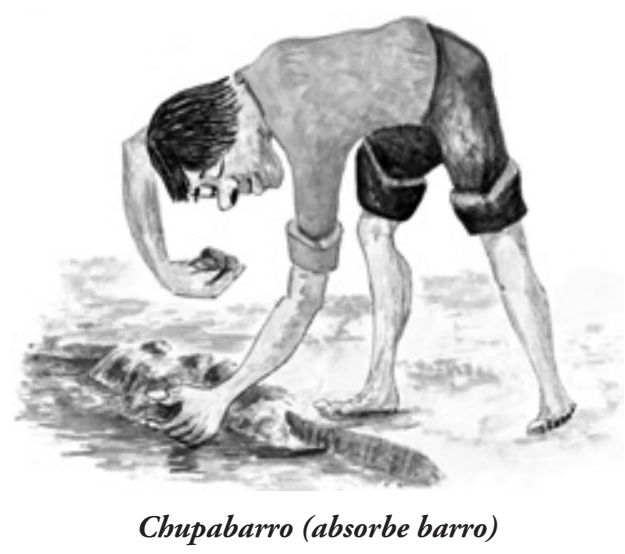

Cabana se crea el 2 de enero de 1857. Una de las más antiguas del reino de los Conchucos. La provincia fue creada mediante ley del 21 de febrero de 1891, con su capital: Cabana.

\section{(Kapsoli, Wilfredo y Ocaña, Helí. Loc. cit.)}

Pallasca proviene de la voz quechua "pallarir" que significa recoger, tomar "ya que en el río Tablachaca o Chuquicara hay oro en pepitas". Cabana proviene de "caguana" que significa mirar, de donde se mira, es decir el mirador.

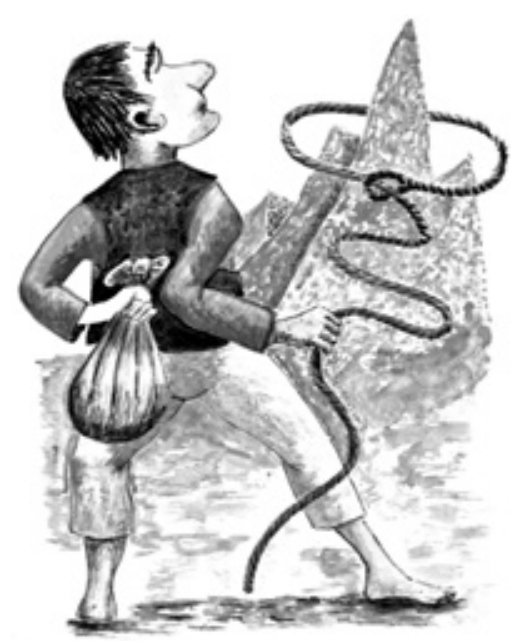

Gagga lazojj (ladronera): Los de Recuay son mineros por naturaleza, dominan los cerros. Ladronzuelos por ańadidura. 
Fue creada por Decreto Ley No 1171 del 30 de setiembre de 1949. En la época preincaica, fue la cuna de la cultura regional, fue uno de los focos más importantes en la zona central andina.

\section{(Kapsoli, Wilfredo y Ocańa, Helí. Loc. cit.)}

Francisco Pizarro, llegó a Recuay al anochecer del 12 de setiembre de 1533, descansando doce días en el pueblo. Cuando realizó la contribución de encomiendas la de Choquericay a Sucoarocuay.

(Kapsoli, Wilfredo y Ocaña, Helí. Op. cit., p. 435).

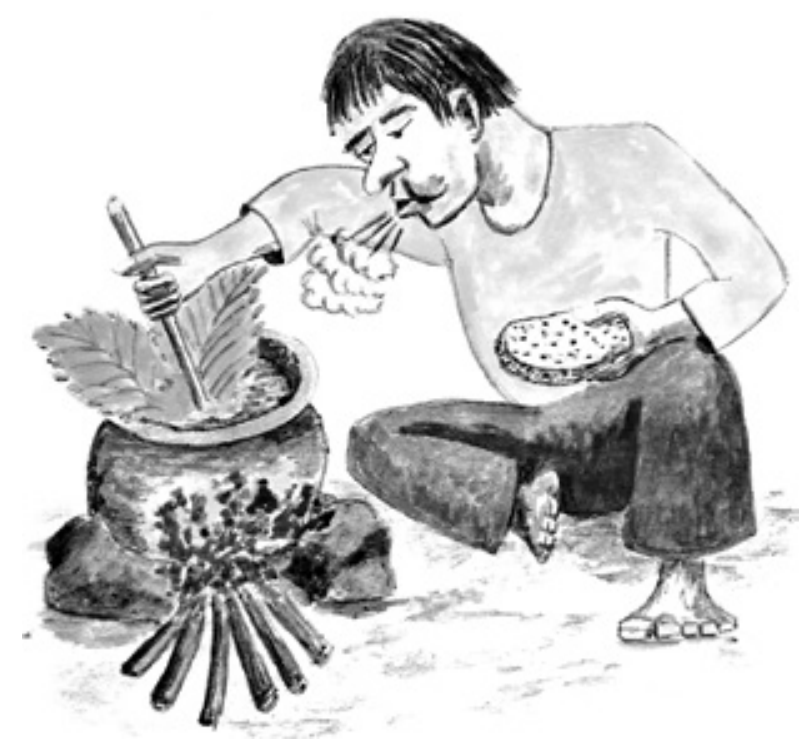

En Putagga cashqui, llullu queso:

Toman sopa de acelgas con queso tierno (fresco).

Hay una gran tradición y personajes característicos de la provincia: la aparición del "Señor de Pomallucay", cuenta que su imagen apareció en una quebrada cuya apariencia intacta generó un sentimiento religioso muy importante es por ello que la comunidad construye una capilla y se realiza el traslado. Pero al día siguiente se dan con la sorpresa que la imagen estaba otra vez en el mismo lugar que lo vieron por primera vez. Así ocurrió una y otra vez hasta que finalmente se quedó en la capilla.

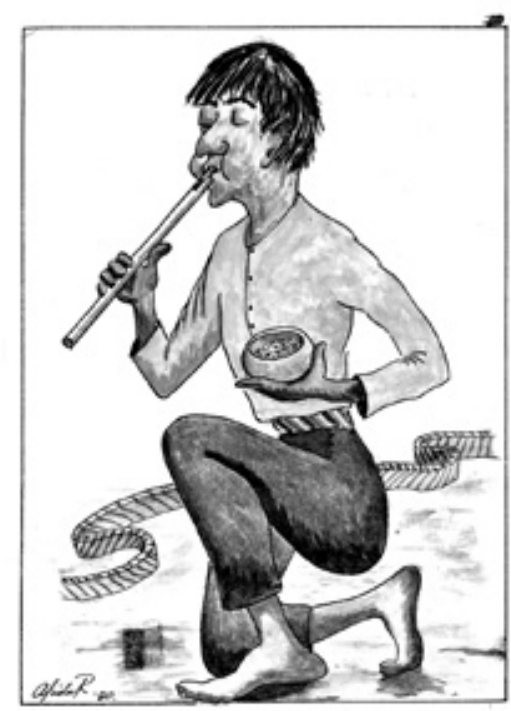

Sihuas: Ají putu, pinkullero: (Intérprete de la flauta).

Ciudad fundada el 5 de agosto de 1543 por el español Juan Gómez Arias “ a la antigua ciudad se le llamó "Chasqui" por haber sido el centro del camino real del Inca”. (Kapsoli, Wilfredo y Ocaña, Helí. Op. cit p. 434). "Sihuas fue desde el 8 de agosto de 1834, hasta el 19 de febrero de 1861, capital de la extensa provincia de Conchucos Bajo" categoría que perdería injustamente. (Kapsoli, Wilfredo y Ocaña, Helí. Loc. cit.)

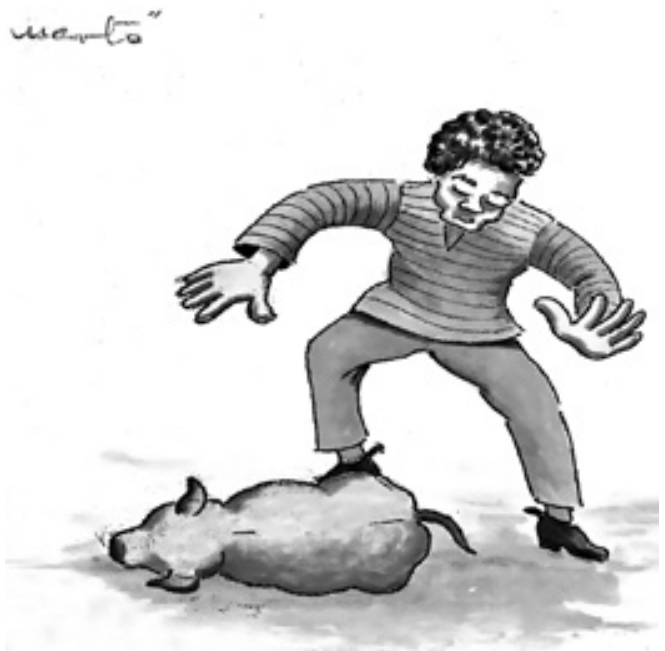

Comemuerto (no desperdician al animal muerto o sea la carroña).

Casma Hasta 1823 fue la capital del Partido de Santa. Exhibe el importante Complejo Arqueológico de Sechín. La provincia de Casma se crea por Decreto Ley No 11326 del 14 de abril de 1950 con el nombre de Huarmey; denominándosele posteriormente Casma por Ley No 12382 de 25 de julio de 1955, siendo su Capital la ciudad del mismo nombre. (Kapsoli, Wilfredo y Ocaña, Helí. Op. cit., p.436). 


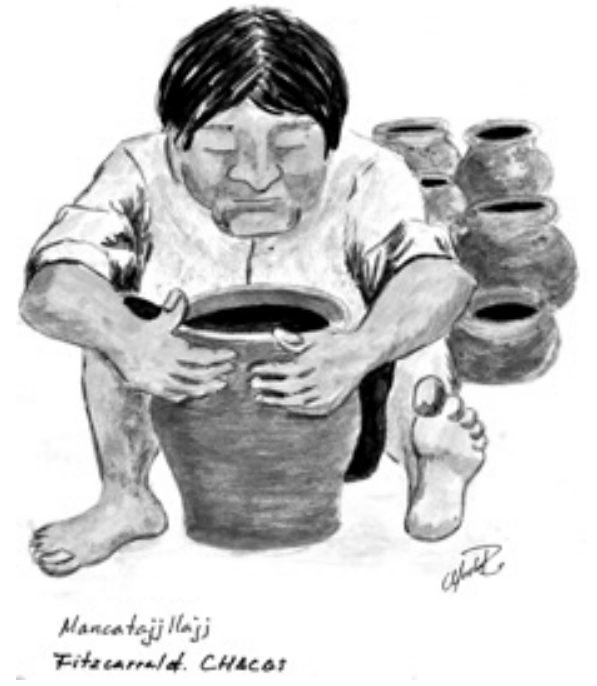

Manca tajjlaj o manca carga (Fabricante y comercializador de ollas de barro)

Asunción se localiza en pleno corazón de la Sierra de Áncash. En la vertiente oriental de la Cordillera Blanca, en el denominado Callejón del Yanamayo gran afluente del Marańon. Tiene por capital al distrito de Chacas, cuenta con dos distritos: Chacas y Acochadas. (Kapsoli, Wilfredo y Ocaña, Helí. Op. cit., p. 437).

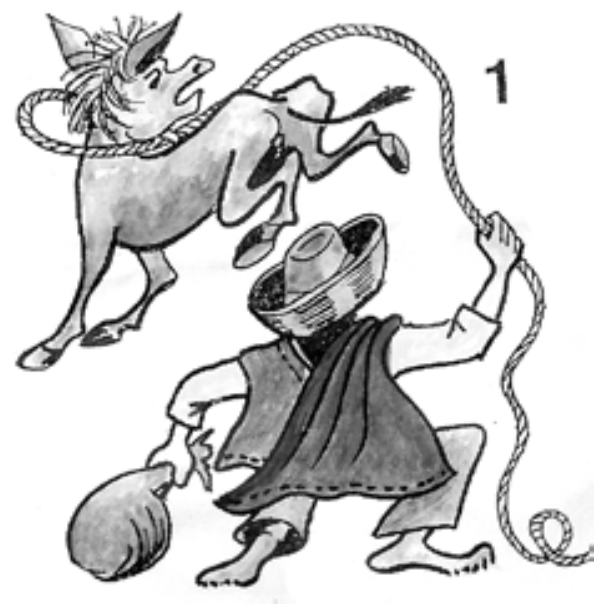

LACIA MULA (abugeo)

Pomabamba es considerada la genuina representante de Conchucos. La villa de Pomabamba es convertida en distrito por Ley del 29 de diciembre de 1856, oficializándose el 2 de enero de 1857. La Ley del 21 de febrero de 1861 promulgada por el Presidente Ramón Castilla, divide Conchucos bajo en dos provincias: Pomabamba y Pallasca. (Kapsoli, Wilfredo y Ocańa, Helí. Op. cit., p. 438).
La palabra Pomabamba deriva de las voces quechuas Pumapampa, que quiere decir: "Llanura de los pumas". A los pobambinos le dicen "lacia mula" por considerarlo abigeos, de especialmente vacunos, caballos y mulas.

\section{Bibliografía}

Alba Herrera, C. A. (2000). Áncash en el Recuerdo y para el Recuerdo. Ediciones El Inca, Mayo. Lima

Alba Herrera, C. A. (2000). Huaylas en la Historia. Ediciones El Inca. Primera Edición, Lima, Julio.

Ángeles Caballero, C. A. (1963). Literatura Peruana. Áncash. Colección Oro, Lima: Talleres Gráficos P.E. Villanueva S.A., Lima - Perú.

Bustos Chávez, C. P. (1962). La vida y obra del sabio Antonio Raimondi. Segunda Edición, Lima: Villanueva.

Córdova Rosas, I. (1986). El diablo en la ideología del mundo andino (El Valle del Mantaro). Huancayo: Gráfica Santa Inés E.I.R.L.

Maguiña Morales, L. (1990). Aija, sus facetas, historia - arte - folklore - la fiesta patronal. Lima: S.F. Editorial Áncash.

Malca, J. (1993). Áncash y su polícroma indumentaria. Primera Edición, Diciembre. Huaylas: Municipalidad Provincial De Huaylas.

Kapsoli Escudero, W. (1993). Cuentos y leyendas conchucanas. Primera Edición Lima: CDIAC.

Kapsoli Escudero, W. (1989). Historia y psicología del indio. Libro 2, Primera Edición. Lima: Biblioteca Andina De Psicología.

Kapsoli Escudero, W. y Ocaña, Helí (2014). Ancash capital cultural y educación. Lima, Ed. Derrama Magisterial.

Salazar Mejía, J. A. (2007). Tradición histórica oral ancashina. Primera Edición. Lima: Editorial San Marcos.

Silva Asencios, P. E. (2000). Llamellin y su fiesta patronal. Primera Edición. Lima: Lluvia Editores.

Yauri Montero, M. (2000). Leyendas ancashinas, toda la magia y el encanto de Áncash milenario. Sexta Edición. Lima: Villanueva.

Recibido: 12 de marzo del 2019.

Aceptado: 16 de marzo del 2019. 